\title{
COMPETÊNCIAS GERENCIAIS E DESEMPENHO FINANCEIRO EM MICRO E PEQUENAS EMPRESAS RURAIS
}

\author{
Adilson Cunha Costa ${ }^{1}$
}

\begin{abstract}
RESUMO
COSTA, A.C. Impacto das competências gerenciais mobilizadas no desempenho financeiro de micro e pequenas empresas rurais. Perspectivas Online: Humanas \& Sociais Aplicadas, v.9, n.24, p.47- 68, 2019.

Uma gestão competente pode ser decisiva para a sobrevivência ou não de qualquer tipo de organização, inclusive para as Micros e Pequenas Empresas- MPEs. E requer também a mobilização $\mathrm{e}$ combinação de um conjunto de competências gerenciais dos gestores à frente de seus empreendimentos. Nesse contexto, essa pesquisa procurou apontar se as competências gerenciais mobilizadas pelos gestores de MPEs rurais têm impacto no desempenho financeiro nesse tipo de

pesquisa teve enfoque quantitativo e descritivo, instrumentalizada através da utilização de um questionário estruturado, respondido por 35 gestores e analisado através das técnicas de estatísticas univariadas, bivariadas e multivariadas. Os resultados através da aplicação da regressão linear múltipla demonstraram que existe relação positiva importante entre a mobilização de algumas competências gerenciais e o desempenho financeiro das MPEs estudadas.
\end{abstract} empresa. Em termos metodológicos essa

Palavras-chave: Gestão; Competências gerenciais; Desempenho financeiro. 


\begin{abstract}
Management can be decisive for the survival or otherwise of any type of Competent organization, including for Micro and Small Enterprises -SMEs. And it also requires the mobilization and combination of a set of managerial skills of the managers in front of their enterprises. In this context, this research sought to indicate if the managerial competencies mobilized by managers of rural SMEs have an impact on the financial performance of SMEs rurais. In methodological terms, this

research had a quantitative and descriptive approach, instrumented through the use of a structured questionnaire, answered by 32 managers and analyzed using univariate, bivariate and multivariate statistical techniques. The results through the application of multiple linear regression demonstrated that there is an important positive relation between the mobilization of some managerial competencies and the financial performance of the MSEs studied.
\end{abstract}

Keywords: Management; Management skills; Financial performance.

\footnotetext{
${ }^{1}$ Mestre em Administração pela Faculdade de Campo Limpo Paulista- Faccamp- Rua Guatemala, 167, Jardim América, Campo Limpo Paulista, São Paulo, SP, CEP:13231-230

(*) e-mail: adiljacosta@yahoo.com.br

Data de recebimento: 24/10/2018. Aceito para publicação: 24/04/2019
}

Persp. online: hum. \& sociais aplicada., Campos dos Goytacazes, 24 (9),47-68, 2019

seer.perspectivasonline.com.br 


\section{INTRODUÇÃO}

As micro e pequenas empresas- MPEs desempenham um papel fundamental na economia mundial contemporânea (SORIANO, 2017; FATOKI, 2014). Em todo o mundo, elas têm ajudado a diminuir a pobreza e a desigualdade social através da criação de empregos, inclusive no setor rural. Na área de abrangência da Organização para a Cooperação e o Desenvolvimento Econômico - OECD, as MPEs representam aproximadamente 99\% de todas as empresas e são a principal fonte de trabalho, respondendo por cerca de $70 \%$ dos empregos (OECD, 2017).

Nos Estados Unidos da América- EUA, as MPEs são 99\% das empresas, contribuem com $46 \%$ do PIB e fornecem 49,2\% da mão de obra empregada ( DAHMEN; RODRIGUEZ, 2014). A participação das MPEs na produção da Alemanha é de $48 \%$, enquanto que o crescimento econômico em muitos países asiáticos, como Coréia, Taiwan e Japão, é diretamente proporcional ao que foi criado pelas atividades das MPEs. Elas também desempenham um papel muito importante na rápida industrialização e desenvolvimento da China, onde aproximadamente 99\% do total das empresas são MPEs (KATUA, 2014).

Em relação ao Brasil, as MPEs estão presentes em todas as regiões de nosso território, destacando-se principalmente no papel de geração de empregos, renda, crescimento econômico e inclusão social ( EVERTON JUNIOR, 2017). Em nosso país, elas representam cerca de $98,2 \%$ das organizações aqui instaladas e $51,2 \%$ da mão de obra empregada formalmente (SEBRAE, 2016). Além disso, as MPEs são as principais formadoras de riqueza em quase todos os setores da nossa economia, correspondendo a 53,4\% do Produto Interno Bruto- PIB do comércio, 22,5\% do PIB da indústria e um terço da produção brasileira do setor de serviços (SEBRAE, 2016). E do total de empresas exportadoras brasileiras as MPEs correspondem à 49,6\% (SECEX, 2016).

Contudo, mesmo com todos esses dados favoráveis para as MPEs, constata-se um alto percentual de fracasso de MPEs em nosso país (SEBRAE, 2016). E na busca de entender quais são os principais fatores relacionados a essa grande mortalidade precoce das MPEs, alguns autores destacam entre eles a fraca competência gerencial (BOHN et al., 2018; SANTINI, 2015; NASCIMENTO et al., 2013; FERREIRA et al., 2012). Nesse sentido, a deficiência no conhecimento e desenvolvimento das práticas gerenciais por parte dos gestores de MPEs têm também contribuído para o baixo desempenho financeiro e o fechamento precoce de muitas dessas instituições.

Em razão disso, o tema competências gerenciais vem sendo cada vez mais ganhando espaço no âmbito das organizações, e ainda recebendo destaque da literatura, principalmente, por sua ligação com assuntos como o desempenho nas empresas (FREITAS; ODELIUS, 2018). Assim, nesse contexto, esse artigo tem por objetivo investigar se as competências gerenciais dos gestores das MPES localizadas na colônia mergulhão, área rural do município de São José dos Pinhais- Paraná, Brasil, têm impacto no desempenho financeiro dessas empresas.

\section{REFERENCIAL TEÓRICO}

\subsection{Competência e competência gerencial}

Persp. online: hum. \& sociais aplicada., Campos dos Goytacazes, 24 (9),47-68, 2019 seer.perspectivasonline.com.br 
No que se refere ao assunto competências, nota-se que ele percorre várias formas de apresentação, não existindo uma conformidade de entendimento no desenvolvimento de seu debate no transcorrer do tempo ( FREITAS; ODELIUS, 2018). Além disso, o tema revela-se complexo, carregado de pormenores e em processo de elaboração (BARBOSA; CINTRA, 2012). Porém, apesar das discordâncias nos conceitos expostos, há duas formas de pensamento na sua exibição, ou seja, a americana e a francesa (SANT'ANNA et al., 2016).

A primeira vertente destaca o conceito de competência, levando em consideração um conjunto de qualificações ou características do indivíduo para determinado cargo, que lhe possibilita alcançar uma performance superior no seu trabalho (BOYATZIS, 2008; SPENCER; SPENCER, 1993; MCCLELLAND, 1973). A segunda ressalta que somente há competência quando existe ação, pois a competência envolve interação e mobilização em determinado contexto (ZARIFIAN, 2012; LE BOTERF, 2011). Por isso, para esta última corrente, não se pode falar em competência apenas no âmbito do conhecimento e da habilidade, mas necessita realizar-se na ação; só há competência quando o sujeito se vale de suas capacidades para resolver determinada situação. Em outras palavras, ter muitos conhecimentos e habilidades não denota ser competente (LE BOTERF, 2011).

Verifica-se na bibliografia brasileira, a influência da corrente francesa e a integração dos conceitos americano e francês para competência. Dessa forma, procura-se evidenciar os conhecimentos, as habilidades, as atitudes, a mobilização, a entrega, a aprendizagem, os resultados e a agregação de valor (DUTRA, 2013; FLEURY; FLEURY, 2011; BITENCOURT; BARBOSA, 2010; RUAS, 2010; SILVA, 2010). Ruas (2010), por exemplo, define competência como "a capacidade de combinar e mobilizar adequadamente recursos já desenvolvidos" (p.46). Nesse sentido, competência não é somente um estoque de capacidades que o indivíduo possui, mas a mobilização desses recursos em determinado contexto. Dutra ( 2013) destaca que para que haja competência os indivíduos precisam transformar seus conhecimentos, habilidades e atitudes em alguma entrega para a instituição que façam parte. Sob esse prisma não existe competência sem que haja incorporação de valores para a organização e a criação de resultados harmonizados com as estratégias organizacionais (DUTRA, 2013; FLEURY; FLEURY, 2011).

No que diz respeito à discussão sobre o conceito de competências gerenciais, Boyatzis (2008) a delineou como uma disposição humana de se conduzir de forma a acolher às exigências do trabalho nos parâmetros dados pelo ambiente da organização e, assim, alcançar os resultados exigidos. Elas são características subjacentes de um indivíduo, que são relacionadas a um desempenho efetivo do cargo de gestor. Esses atributos são observáveis, demonstráveis e inferidos, e quando alcançados demonstram a diferença entre o desempenho de um gestor com competência e outro sem competência.

Le Boterf (2011) afirmou que as competências gerenciais não estão unicamente vinculadas por si só às qualificações do indivíduo, mas também ligadas à mobilização de vários conhecimentos e habilidades em diferentes situações. Para esse autor, as competências gerenciais não são elas próprias recursos no sentido de saber como agir, saber fazer ou atitudes, mas a mobilização, a integração e a combinação de tais recursos em um contexto específico de gestão. Elas não são um estado, mas estão ligadas à ação. Ele também buscou posicionar as competências gerenciais num eixo convergente entre a pessoa (biografia pessoal) e sua própria formação educacional e experiência profissional.

Esses três pontos de convergência de Le Boterf (2011) são importantes no âmbito desta pesquisa porque quando se trata de competências gerenciais em micro e pequenas

Persp. online: hum. \& sociais aplicada., Campos dos Goytacazes, 24 (9),47-68, 2019

seer.perspectivasonline.com.br 
empresas, que é o caso, é preciso lembrar que muitas dessas organizações são alicerçadas na pessoa de próprio proprietário ou gestor. E estes, quando tomam decisões de negócios, dentro de uma determinada realidade, são motivados, também, pela história de vida pessoal, educacional e experiência profissional.

Nessa mesma linha de pensamento, para Zarifian (2012), a competência gerencial deve ser vista como uma atuação por meio da qual o gestor mobiliza seus conhecimentos, habilidades e atitudes com o objetivo de realizar sua incumbência em determinada conjuntura profissional em que está inserido.

Numa concepção também abrangente, as competências gerenciais, para Larentis et al. (2012), envolvem a compreensão do negócio, a identificação de oportunidades e de ameaças, os pontos fortes e fracos da organização, ter uma orientação para o mercado (clientes, comerciantes) e para as necessidades e exigências dele e saber planejar, organizar e mobilizar recursos. Por isso, um gestor eficiente precisa compreender tudo ao seu redor e também os acontecimentos do ambiente externo, assim como toda sua equipe precisa estar conectada com todo o contexto da organização. Nessa contexto, as empresas precisam de gestores que possuam não somente conhecimentos técnicos e do negócio, mas todos os que foram adquiridos por meio de outras experiências. Daí a necessidade de aumentar a capacitação dos gestores, com o objetivo de alcançar um melhor resultado possível para a organização.

Mintzberg (2010) foca as competências gerenciais numa variedade de condutas e habilidades empregadas pelo gestor na solução de problemas dentro do ambiente de trabalho. O que diferencia os estudos desse autor de outras pesquisas é a observação direta que fez das atividades de trabalho dos gerentes no cotidiano. Ele não se limitou a definir e mostrar as competências que os gerentes deveriam apresentar, mas empreendeu um estudo empírico com executivos em cinco organizações diferentes. A partir disso, ele identificou vários papéis que descrevem a variedade do trabalho do gestor, concluindo que não há uma única maneira de gerenciar com eficiência e eficácia.

Para Fleury e Fleury (2011), as competências de um gestor estão associadas ao saber agir, mobilizar, comunicar, aprender, comprometer-se, assumir responsabilidades e ter visão estratégica. Essas características, segundo os autores, evidenciados no aspecto de verbos, trazem consigo uma concepção prática, ou seja, demonstram ação, prática, movimento, habilidade prática. Nessa perspectiva, a competência gerencial é saber agir responsável do gestor que envolve mobilizar, integrar, transferir conhecimentos, recursos e habilidades que adicionem valor econômico à organização.

Esses autores classificam as competências gerenciais desenvolvidas por indivíduos em três dimensões: (1) competências de negócios: relacionadas à compreensão do negócio e de seus objetivos na relação com mercado, clientes e competidores assim como do ambiente político e social, por exemplo, visão estratégica, planejamento, orientação para o cliente, etc. (2) competências técnico-profissionais: específicas para uma operação, ocupação ou atividade. São informações e conhecimentos técnicos relativos à área de atuação, que devem ser utilizadas e atualizadas constantemente, visando ao cumprimento de atividades, à resolução de problemas, ao conhecimento do produto/serviço, das finanças, da gestão de operações, etc. (3) competência social: necessárias para interagir com as pessoas, como, por exemplo, comunicação, negociação, mobilização para mudanças, sensibilidade cultural, trabalho em equipe, etc. 
Para esse estudo específico das competências gerenciais nas MPEs, a escolha dessas categorias de Fleury e Fleury (2011) se justifica porque nessas organizações o administrador é a peça fundamental do processo da elaboração de estratégia. E, por isso, ele precisa estar capacitado para a gestão dos negócios, que envolve mobilizar habilidades pessoais, sociais e conhecimentos técnicos profissionais, por exemplo, de administração, de aplicação em situações de direção, coordenação, planejamento, liderança, etc.

\subsection{Desempenho Financeiro}

No aspecto desempenho financeiro em Micros e Pequenas Empresas. em razão da ampla concorrência, nos dias atuais, é de vital relevância que as empresas, independentemente de qualquer tamanho ou setor, procurem implantar sistemas de medição de desempenho. Aferir o desempenho torna-se crucial porque ajuda a organização assegurar "a conformidade, verificar e questionar" (HAUBERT; NASCIMENTO, 2013, p. 8). Em outras palavras, permite entender como ela está progredindo, no sentido de alcançar seus objetivos, por meio do monitoramento contínuo daquilo que foi planejado (SOUZA et al., 2014).

O uso de medidas de desempenho financeiro ainda é a forma mais corriqueira e sobre a qual há muitas pesquisas corroborando com sua eficácia (MACEDO et al., 2012). Em razão disso, destaca-se a necessidade de aferir o desempenho financeiro das organizações, visto que elas são criadas para atingir resultados favoráveis e, por isso, medi-lo é essencial (MACEDO et al., 2012). Existem várias formas ou diferentes tipos de indicadores de desempenho financeiro, porém, escolher indicadores mais acertados, para avaliar as organizações, muitas vezes, não deixa de trazer consigo uma certa subjetividade (SOUZA et al., 2016; NASCIMENTO et al., 2011).

Alguns autores apresentam duas formas de medir o desempenho financeiro: uma objetiva e a outra subjetiva (VIJ; BEDI, 2016; LANDRY; SCHIEHLL, 2014; ZULKIFFLI, 2014; YILDIZ; KARAKAS, 2012; WEGNER; MISOCSKY, 2010; SCHACHTER, 2010). A primeira é baseada, por exemplo, em dados financeiros, contábeis e econômicos como faturamento, número de funcionários, resultado operacional, crescimento de vendas, crescimento de lucros etc. E a segunda, no juízo dos entrevistados sobre algum aspecto da atuação da empresa (PALMA et al., 2014; SCHMIDT; BOHNENBERGER, 2009).

Nas MPEs, quando se trata de medir o seu desempenho, seja pelos aspectos objetivos ou subjetivos, torna-se ainda mais complicado, pelo motivo de que esse tipo de avaliação quase não existe nessas empresas (SANTANA; CUNHA; MARIZ , 2016; CARDOSO et al., 2014; PASSOS; SPERS, 2014). Além do que, as exigências legais, tributárias e contábeis para as MPEs são menos complexas, resultando, por exemplo, em controles contábeis e financeiros básicos, na falta de uma contabilidade estruturada para a elaboração de demonstrações contábeis adequadas e em dados fornecidos não completos e nem precisos. (REIS NETO et $a l ., 2013$ ).

Dentro dessa realidade, e em razão também que as MPEs têm aspectos organizacionais e características peculiares que as distinguem das grandes empresas como a centralização das decisões na pessoa do seu proprietário e a sua estrutura organizacional simples, que, de uma forma ou outra, acabam sendo determinantes para o seu desempenho financeiro (ESPEJO; LEITE, 2016), a utilização de dados das práticas gerenciais dos gestores de micro e pequenas empresas em relação ao seu desempenho financeiro, para pesquisas sobre essas empresas, vem tendo o aceite da literatura semelhante no tema ( BRYSON; FORT 2018; VELIU; MANXHARI, 2017; BROSZEIT et al., 2016; FREIRE, 2016; ESPEJO; LEITE, 2016; 
SANTOS et al., 2016; HAYTON, 2015; MACHADO et al., 2015; WU et al.,2015; FATOKI, 2014; LEMOS; PICCHIAI, 2014; SIDEK; MOHAMAD, 2014; SOUZA; CORREA, 2014; SHEEHAN, 2013).

\section{METODOLOGIA}

\subsection{Delineamento da pesquisa}

Quanto a natureza essa pesquisa foi quantitativa porque foram obtidos dados numéricos de uma determinada amostra, medida e averiguada a ligação entre variáveis, aplicando-se técnicas de estatísticas univariadas (percentuais, médias, desvio padrão, etc.), bivariadas (correlações) e multivariadas- regressão linear múltipla (RICHARDSON, 2017; CRESWELL, 2014; HAIR. et al., 2014). E, em relação aos fins, teve o enfoque descritivo, porque se procurou identificar, descrever, classificar, analisar, interpretar e relacionar variáveis das características de um determinado fato ou acontecimento (RICHARDSON, 2017). Nesse caso, do perfil geral dos gestores respondentes e de seus empreendimentos, das competências gerenciais avaliadas pelos gestores e desta última em relação ao desempenho financeiro de suas MPEs.

\subsection{Universo da amostra, amostra e principal instrumento para a coleta dos dados}

A população desse estudo é composta por um grupo de 39 micro e pequenas empresas situadas na região metropolitana, área rural do município de São José dos Pinhais, no Estado do Paraná. O critério adotado para a classificação das micro e pequenas empresas foi o do SEBRAE (2014). Segundo Leone e Leone (2012), esse é um dos mais divulgados e de mais fácil acesso a dados. Nesse caso, define-se microempresas do setor da indústria aquelas com até 19 funcionários e do comércio e serviços, com até 9 funcionários. Já as pequenas empresas da indústria com 20 a 99 funcionários e do comércio e serviços com 10 a 49 funcionários.

A amostra da presente pesquisa caracterizou-se como não probabilística, selecionada por conveniência e não aleatoriamente (MALHOTRA, 2012). Utilizou-se, como principal instrumento de pesquisa, um questionário estruturado com perguntas fechadas, adaptado de Costa (2016), que foi respondido por 35 gestores de MPEs. Esse questionário foi dividido em duas partes: na primeira, constavam 14 perguntas gerais sobre o perfil do gestor e de seu empreendimento e na segunda, solicitava aos respondentes que indicassem, através de uma escala Likert de 5 pontos, a sua percepção em cada uma das 30 proposições de competências gerenciais levantadas de acordo com o referencial teórico de Dutra (2013), Le Boterf (2011), Fleury e Fleury (2011) e Ruas (2010).

Numa fase seguinte foi analisada a confiabilidade da aplicação da principal ferramenta de pesquisa utilizada, por meio do coeficiente do alfa de Cronbach $(\alpha)$. De um modo geral, um instrumento de pesquisa é considerado como tendo credibilidade quando o valor do $\alpha$ é pelo menos 0.70 (SOUZA et al., 2017; HAIR et al., 2014). Entretanto além de avaliar esse resultado, outro fator essencial que se deve estar alerta é sobre a correlação entre o escore de cada um dos itens a serem analisados e a soma dos escores dos demais itens do instrumento. Para que a correlação do item, em relação ao conjunto dos itens, seja admissível, o resultado de seu escore deve ser no mínimo de 0,40 (HAIR et al., 2014). Itens com valores abaixo desse escore, devem ser eliminados.

Persp. online: hum. \& sociais aplicada., Campos dos Goytacazes, 24 (9),47-68, 2019 seer.perspectivasonline.com.br 


\subsection{Tratamento e Análise de Dados}

As informações coletadas mediante o questionário foram processadas e avaliadas estatisticamente através do software SPSS versão 19.0 (Statistical Package for the Social Sciences) em três momentos: No primeiro, foram trabalhados os dados através da estatística descritiva (frequências relativas e absolutas) paras variáveis do perfil dos respondentes e de seus empreendimentos. Na segunda também mediante a estatística descritiva (média e desvio padrão) analisaram-se as competências gerenciais avaliadas pelos gestores.

Posteriormente foi constatada a normalidade da amostra, através da aplicação do teste de Shapiro-Wilk (MAROCO, 2014; MALHOTRA, 2012). Em razão disso, foi empregada a técnica de estatística bivariada de correlação de Pearson que avaliou quais das variáveis independentes, de fato, das hipóteses levantadas, tinham alguma relação com a variável dependente o desempenho financeiro (faturamento médio), para, assim, definir o modelo inicial da regressão linear a ser testado. Para tanto, o nível de significância adotado foi igual a 0,05 , ou seja, se o valor da coluna $\mathrm{P}$ - valor for $<0,05$, havia correlação entre as variáveis testadas, caso contrário não.

A partir dessas correlações, realizou-se a análise de regressão linear, objetivando verificar quais das variáveis independentes correlacionadas com a variável dependente tinham impacto sobre esta última. Empregou-se o método de regressão linear múltipla, que tem como finalidade testar o grau de relacionamento entre uma variável dependente e duas ou mais varáveis independentes, (HAIR et al., 2014). Foram excluídas do exame as variáveis que não se correlacionaram com a variável dependente. Além disso, para a validação do modelo de regressão linear múltipla aplicado, foram verificados os seguintes pressupostos: inexistência de autocorrelação dos resíduos, homocedasticidade ou linearidade dos resíduos, normalidade dos resíduos, colineariedade das variáveis independentes, ausência de erros de especificação e falhas estruturais não encontradas no modelo da regressão linear (HAIR et al., 2014; MAROCO, 2014).

\subsection{Variáveis independentes e dependente do modelo de regressão linear}

As variáveis independentes são formadas pelos itens de competências gerenciais avaliadas pelos gestores divididas em três categorias, decorrentes dos conhecimentos, atualização e monitoramento do negócio, das habilidades técnicas e profissionais na gestão do negócio e do relacionamento interno e externo. Já a variável dependente, pelo fato da restrição de se encontrar medidas de desempenho próprias para MPEs, e levando em consideração que "a maioria das variáveis que medem o desempenho de uma organização são baseadas em dados financeiros tais como rentabilidade e média do faturamento"( FREIRE, 2016: p.2), assumiu-se, para esse estudo, esse último fator como indicador de medida do desempenho financeiro. Além disso, defende-se a preferência por essa variável, em razão de que "qualquer impacto no faturamento pode afetar diretamente outros itens de funcionamento das MPEs, principalmente nas entradas e saídas de recursos financeiros" (LEMOS; PICCHIAI, 2014, p.16).

\section{RESULTADOS E DISCUSSÃO}

\subsection{Perfil geral dos gestores respondentes e de seus empreendimentos}

Persp. online: hum. \& sociais aplicada., Campos dos Goytacazes, 24 (9),47-68, 2019 seer.perspectivasonline.com.br 
A distribuição dos respondentes de acordo com o seu gênero mostra que $61,76 \%$ são homens e $38,24 \%$, mulheres. Destaca-se a frente da gerência desses estabelecimentos rurais, um percentual considerável de mulheres. Estas cada vez mais presentes no mercado de trabalho, nas mais variadas profissões, inclusive na gestão de MPEs no setor rural. Constatouse que $96,88 \%$ dos estabelecimentos são gerenciados pelo próprio proprietário e o restante por pessoas contratadas de fora da família do dono. No quesito faixa etária, $61,77 \%$ dos gestores respondentes da pesquisa têm idade acima de 40 anos e 38,23\% igual ou inferior a 40 anos. No aspecto escolaridade, a maioria dos empreendedores cursou, no mínimo, ensino médio. Somando as porcentagens dos que têm segundo grau completo e ensino superior, chega-se a $60,6 \%$ do total dos empreendedores.

Antes de investir no empreendimento atual 47,05\% dos proprietários exerciam alguma atividade na agricultura local. Hoje apenas $12,50 \%$ destes exercem atividade na agricultura e $44,11 \%$ não exercem outra atividade paralela ao de gestor. Separadas as MPEs por atividades afins tem-se que $64,64 \%$ é do setor da alimentação, seguidos pelo ramo do comércio de vinho que correspondem a $32,36 \%$ e $3,0 \%$ do comércio e serviços ao mesmo tempo. Já pelo porte, $79,41 \%$ são microempresas e $20,59 \%$, pequenas empresas. $88,24 \%$ dos estabelecimentos são próprios e $11,76 \%$ alugados. No que diz respeito à longevidade das empresas, a maioria, 18 empresas, concentram-se na faixa de 11 a 18 anos de existência na região, representando em percentuais no total 56,25\%. Entre 6 e 10 anos tem-se 4 estabelecimentos (12,50\%) e na faixa de 1 a 5 anos, 31,25\% das empresas. Infere-se que a maioria dessas MPEs já alcançou o estágio de maturidade, que ocorre quando se ultrapassa cinco anos de sobrevivência (SANTOS; DOROW; BEUREN, 2016).

Sobre a principal motivação para a constituição da empresa no local, a pesquisa levantou que $40,63 \%$ dos gestores iniciaram seus negócios em razão da tradição familiar, ou seja, a família pais ou avós já tinham anteriormente uma atividade ou negócio no local, principalmente advinda da agricultura familiar. $\mathrm{O}$ segundo fator mais citado na pesquisa para a abertura do negócio foi o fato de o proprietário ou gestor conhecer o ramo do negócio $(28,12 \%)$. Nesse aspecto, segundo a literatura, há certos pressupostos essenciais para o êxito empresarial familiar, entre eles a atenção à tradição familiar e para o conhecimento do negócio (BELMONTE; FREITAS, 2013).

$\mathrm{Na}$ questão número de funcionário contratados, de acordo com o setor de atividade, o segmento do comércio e serviço emprega mais, $72,15 \%$ do total. Nesse âmbito os que mais contratam são os estabelecimentos da área da gastronomia e a atividade indústria e comércio admite apenas $11,81 \%$. No geral, $46,41 \%$ da mão de obra contratada são familiar e $53,59 \%$ fora da família do proprietário. Em relação ao faturamento médio alcançado com o empreendimento, encontram-se $21,88 \%$ das empresas com média de renda de 150.000,00 e $21,88 \%$, com média de renda de $360.000,00$. O resultado alcançado com o empreendimento para $52,94 \%$ dos gestores entrevistados é o lucro e para $47,06 \%$, para se manter. No aspecto da conformidade da renda alcançada com o empreendimento para $61,76 \%$ dos respondentes complementa a renda, enquanto que para $38,24 \%$ é a renda principal.

\section{2 As competências gerenciais avaliadas pelos gestores}

Primeiramente, através da análise do coeficiente Alfa de Cronbach $(\alpha)$, verificou-se a confiabilidade do principal instrumento utilizado para a coleta de dados dessa pesquisa, individualmente para as 30 proposições de competências gerenciais no geral, como para as três dimensões de macro competências, definidas com base no arcabouço teórico sobre o tema. E chegou-se aos seguintes resultados apresentados nas Tabela 1 e 2.

Persp. online: hum. \& sociais aplicada., Campos dos Goytacazes, 24 (9),47-68, 2019 seer.perspectivasonline.com.br 
Esse indicador assume valores entre 0 e 1 e, de maneira geral, considera-se que um bom valor do $\alpha$ seria 0,70 ou superior (HAIR et al., 2014). O resultado de 0,848, para essa pesquisa, indica uma boa consistência e um alto grau de confiança no geral para as 30 variáveis. Entretanto ao se avaliar a correlação entre o escore de cada um dos itens e a soma dos escores dos demais itens do instrumento, alguns itens estavam com valores abaixo do escore mínimo aceito que é de 0,40 (HAIR et al., 2014). No presente caso, 05 proposições foram eliminadas porque não obedeciam ao critério do escore mínimo, restando 25 itens validados, sintetizados na tabela 1, calculados com suas médias e desvio padrão, em suas respectivas categorias.

Tabela 1: As competências gerenciais avaliadas em suas categorias

\begin{tabular}{|c|c|c|c|}
\hline $\mathbf{N}^{\mathbf{o}}$ & Proposições de competências avaliadas (P) & Média & $\begin{array}{l}\text { Desvio } \\
\text { Padrão }\end{array}$ \\
\hline & $\begin{array}{l}\text { Competências gerenciais mobilizadas em decorrência dos conhecimentos, } \\
\text { das atualizações e do monitoramento sobre o ambiente competitivo do } \\
\text { negócio }\end{array}$ & & \\
\hline P1 & $\begin{array}{l}\text { As metas e os objetivos que tenho traçado, para o estabelecimento que } \\
\text { administro, têm ajudado a trazer bons resultados para este negócio. }\end{array}$ & 3,94 & 1,22 \\
\hline P2 & $\begin{array}{l}\text { O conhecimento do diferencial competitivo de meus concorrentes tem sido } \\
\text { utilizado para melhorar o desempenho do negócio que administro. }\end{array}$ & 3,16 & 1,64 \\
\hline & $\begin{array}{l}\text { Os conhecimentos e informações úteis que tenho sobre meus clientes } \\
\text { permitem a implantação de ideias criativas que possibilitam aumentar minha } \\
\text { vantagem competitiva. }\end{array}$ & 4,06 & 1,11 \\
\hline & $\begin{array}{l}\text { O conhecimento do mercado de atuação do negócio que administro tem } \\
\text { possibilitado decisões para a sobrevivência e a prosperidade deste negócio. }\end{array}$ & 4,19 & 1,20 \\
\hline P6 & $\begin{array}{l}\text { As informações que tenho sobre os hábitos, costumes e as tradições da região } \\
\text { onde se localiza o negócio que administro têm mobilizado ideias que estão } \\
\text { contribuindo para uma maior rentabilidade deste empreendimento. }\end{array}$ & 3,63 & 1,48 \\
\hline P7 & $\begin{array}{l}\text { Tenho buscado informações e conhecimentos de negócios com outros } \\
\text { gestores de outros empreendimentos similares, e, ao utilizá-los, tenho } \\
\text { conseguido bons resultados. }\end{array}$ & 3,53 & 1,46 \\
\hline P8 & $\begin{array}{l}\text { O conhecimento das exigências legais e tributárias para o funcionamento do } \\
\text { estabelecimento que administro está contribuindo para a tomada de decisões } \\
\text { gerenciais importantes sobre o negócio. }\end{array}$ & 4,38 & 1,00 \\
\hline P9 & $\begin{array}{l}\text { Procuro conhecer os produtos dos meus concorrentes e suas qualidades, e, } \\
\text { com base nessas informações, tenho melhorado a qualidade dos produtos e } \\
\text { serviços do empreendimento que administro. }\end{array}$ & 3,47 & 1,61 \\
\hline & $\begin{array}{l}\text { Competências gerenciais mobilizadas em decorrência das habilidades } \\
\text { técnicas e profissionais na gestão do negócio }\end{array}$ & & \\
\hline & $\begin{array}{l}1 \text { Consigo fazer o cliente que frequenta o estabelecimento que administro } \\
\text { perceber o diferencial e a qualidade do produto ou do serviço que ofereço. }\end{array}$ & 4,67 & 0,48 \\
\hline & $\begin{array}{l}3 \text { Faço orçamento e controle das receitas e despesas deste negócio, e com isso } \\
\text { consigo acompanhar a saúde financeira deste negócio. }\end{array}$ & 4,19 & 1,28 \\
\hline & $\begin{array}{l}4 \text { Monitoro a qualidade do(s) produto(s) vendido(s) ou do(s) serviço(s) que } \\
\text { presto como administrador deste empreendimento, e, com isso, tenho } \\
\text { alcançado algumas vantagens competitivas. }\end{array}$ & 4,59 & 0,76 \\
\hline \multicolumn{2}{|r|}{ P16 Com o objetivo de melhorar o desempenho presente e futuro deste negócio } & 4,38 & 1,13 \\
\hline
\end{tabular}

Persp. online: hum. \& sociais aplicada., Campos dos Goytacazes, 24 (9),47-68, 2019 seer.perspectivasonline.com.br 


\begin{tabular}{|c|c|c|}
\hline $\begin{array}{l}\text { que administro, tenho feito uso de informações contábeis e financeiras úteis } \\
\text { em minhas decisões. }\end{array}$ & & \\
\hline $\begin{array}{l}\text { P17 Já implantei mudança(s) que tem(têm) melhorado o desempenho competitivo } \\
\text { do empreendimento que gerencio. }\end{array}$ & 4,56 & 0,95 \\
\hline $\begin{array}{l}\text { P18 Como administrador deste negócio, tenho atraído novos clientes, e, com isso, } \\
\text { melhorado os resultados. }\end{array}$ & 4,53 & 0,92 \\
\hline $\begin{array}{l}\text { P19 Consigo manter os clientes fiéis aos produtos ou serviços que são oferecidos } \\
\text { neste estabelecimento. }\end{array}$ & 4,56 & 0,88 \\
\hline $\begin{array}{l}\text { P20 } \\
\text { Para melhorar o desempenho do estabelecimento que administro, faço uso das } \\
\text { sugestoços prestados. }\end{array}$ & 4,25 & 1,17 \\
\hline \multicolumn{3}{|l|}{$\begin{array}{l}\text { Competências gerenciais mobilizadas em decorrência do relacionamento } \\
\text { interno e externo }\end{array}$} \\
\hline $\begin{array}{l}\text { P21 Tenho valorizado, na administração deste empreendimento, a educação e } \\
\text { cortesia para com clientes e funcionários, visando mobilizar uma melhor } \\
\text { imagem do estabelecimento. }\end{array}$ & 4,75 & 0,57 \\
\hline $\begin{array}{l}\text { P22 A maneira pela qual me comunico com os clientes ou funcionários do } \\
\text { estabelecimento tem sido importante para ampliar a boa imagem do } \\
\text { empreendimento que administro. }\end{array}$ & 4,75 & 0,67 \\
\hline $\begin{array}{l}\text { P23 Tenho sido flexível e aberto às mudanças necessárias que têm melhorado a } \\
\text { vantagem competitiva do estabelecimento que administro. }\end{array}$ & 4,38 & 1,04 \\
\hline $\begin{array}{l}\text { P24 } \begin{array}{l}\text { Tenho ouvido funcionários e parentes que trabalham no estabelecimento que } \\
\text { administro sobre possíveis sugestões que contribuam para o melhoramento do } \\
\text { desempenho do estabelecimento. }\end{array} \\
\end{array}$ & 4,03 & 1,33 \\
\hline $\begin{array}{l}\text { P25 Participo de grupos ou associações ligados ao meu empreendimento, e, por } \\
\text { isso, estou buscando outras soluções que agreguem valor competitivo para o } \\
\text { estabelecimento que administro. }\end{array}$ & 4,25 & 1,344 \\
\hline $\begin{array}{l}\text { P26 Minha conduta ética, na administração deste estabelecimento, tem reflexo } \\
\text { positivo na opinião dos clientes e da comunidade local sobre este } \\
\text { estabelecimento. }\end{array}$ & 4,56 & 0,98 \\
\hline $\begin{array}{l}\text { P27 Faço uso de práticas ambientais positivas no contexto do negócio que } \\
\text { administro e, em razão disso, estou contribuindo para uma imagem positiva } \\
\text { do estabelecimento. }\end{array}$ & 4,59 & 0,76 \\
\hline $\begin{array}{l}\text { P28 Consigo pedir e avaliar opiniões quando tenho que tomar decisões sobre o } \\
\text { negócio que gerencio. }\end{array}$ & 4,16 & 1,17 \\
\hline $\begin{array}{l}\text { P29 Procuro meios de divulgar os produtos ou serviços do empreendimento que } \\
\text { administro e, com isso, tenho melhorado efetivamente minha clientela e } \\
\text { minha rentabilidade. }\end{array}$ & 4,00 & 1,37 \\
\hline
\end{tabular}

Fonte: Dados da pesquisa (2018). Extraídos do software SPSS 19.0.

A partir desses dados levantados na tabela 1, analisaram-se os resultados da média aritmética e o desvio-padrão de cada uma das três categorias de competências gerenciais mobilizadas, com o objetivo de demonstrar o nível de concordância ou discordância dos respondentes. Quanto maior a média, maior é a percepção do gestor quanto ao nível de emprego das competências avaliadas no estudo. Como a escala utilizada variava de 1 a 5, considerou-se que se a média fosse valor igual ou superior a 3,5 seria satisfatório considerar que a competência avaliada era praticada pelo gestor. Porém, destaca-se que valores próximos de 5, maior foi a auto avaliação do gerente, em razão de que 5 é a alternativa que o gestor não deixa de praticar a competência na gestão de seu empreendimento. 
No exame das três categorias de competências gerenciais nota-se na tabela 01 que as com maiores médias e empatadas em primeiro lugar, e, portanto, as mais valorizadas na visão dos entrevistados encontram-se dentro da dimensão relacionamento interno e externo que são respectivamente: a $\mathrm{P} 21$ em que o gestor avaliou a valorização da educação e cortesia para com funcionários e clientes, objetivando uma melhor imagem do estabelecimento (média $4,75)$ e a P22 em que ele examinou a maneira que se comunica com funcionários e clientes e a importância disso para ampliar a boa imagem do empreendimento (média 4,75). Essas duas competências, aludidas nos estudos de Fleury e Fleury (2011), mostram a capacidade do gestor de mobilizar sua atenção na relação que se tem com os colaboradores internos (funcionários) e externos (clientes) no dia do exercício de sua gestão. Aliás, o relacionamento bem de perto entre o proprietário ou gestor com colaboradores e clientes, corriqueiro nas MPES, pode servir de explicação para a grande valorização atribuída pelos entrevistados para a mobilização dessa prática gerencial.

Já a segunda competência gerencial mais destacada positivamente na visão dos gestores foi a P11 em que os gestores conseguem fazer o cliente que frequenta o estabelecimento perceber o diferencial e a qualidade do produto ou do serviço que é oferecido (media 4,67). Esta competência encontra-se na categoria das habilidades técnicas e profissionais na gestão do negócio. Torna-se fundamental, nesse sentido, que os proprietários ou gestores dessas MPEs, como requisito para o êxito de seu empreendimento, sejam capazes de se empenhar na apresentação aos seus clientes de produtos ou serviços cada vez mais de qualidade, e que sejam efetivamente a melhor escolha em detrimento de outros similares oferecidos por outras organizações próximas e concorrentes. Assim, é essencial e pertinente o compromisso com uma permanente gestão de qualidade por parte de proprietários e gestores (FLEURY; FLEURY, 2011; RUAS, 2010).

Dentro da categoria mobilizada em decorrência dos conhecimentos, das atualizações e do monitoramento sobre o ambiente competitivo do negócio, ou seja, aquela direcionada, por exemplo, para a prática dos conhecimentos do mercado, concorrência, legislação, perfil de clientes, etc. ( LE BOTERF, 2011; FLEURY; FLEURY, 2011; RUAS, 2010), encontram-se as variáveis que apresentaram o resultado com menor média, inclusive com duas abaixo do escore mínimo favorável de média adotado $(3,5)$, que são: a $\mathrm{P} 2 \mathrm{em}$ que o gestor aferiu se o conhecimento do diferencial competitivo de seus concorrentes tem sido utilizado como estratégia para melhorar o desempenho do negócio que administra ( média 3,16) e se ele procura conhecer os produtos dos seus concorrentes e suas qualidades, visando mobilizar com essas informações, a melhoria da qualidade dos produtos e serviços oferecidos no empreendimento que administra ( média 3,47 ).

Essas duas competências, relacionadas com orientação estratégica, destacam que as empresas para sua sobrevivência e relevância, em relação aos seus concorrentes, precisam proporcionar produtos ou serviços que sejam reconhecidos pelos seus clientes (FLEURY; FLEURY, 2011). E, para isso, os gestores devem estar atentos às novidades de seu segmento de mercado e para as vantagens competitivas de seus concorrentes, em razão de que também são elementos externos essenciais para avaliar o desempenho e a qualidade de sua gestão.

Ademais, analisando-se o resultado do desvio-padrão (tabela 1), no geral, constata-se que os maiores valores encontram-se nas competências com escores de média menores, notando-se uma maior oscilação das respostas em torno da média com valores mínimos 1,61 (P2) e máximo de 1,64 (P9) de desvio padrão. Em outras palavras, houve razoável divergência na apreciação desses itens menos apreciados, traduzindo-se no seu pouco valor na percepção dos gestores (média baixa) e com considerável desacordo entre as opiniões externadas por

Persp. online: hum. \& sociais aplicada., Campos dos Goytacazes, 24 (9),47-68, 2019 seer.perspectivasonline.com.br 
eles (desvio padrão alto). Na tabela 2, apresentam-se as médias e os desvios padrão em cada uma das três categorias das proposições de competências de gestão apreciadas.

Tabela 2: Resultado da média, por categoria de competências gerenciais avaliadas

\begin{tabular}{|l|c|c|}
\hline \multicolumn{1}{|c|}{ Categoria } & Média & Desvio \\
\hline $\begin{array}{l}\text { Competências gerenciais mobilizadas em decorrência dos conhecimentos, da } \\
\text { atualização e do monitoramento do ambiente competitivo do negócio. }\end{array}$ & 3,79 & 1,34 \\
\hline $\begin{array}{l}\text { Competências gerenciais mobilizadas em decorrência das habilidades técnicas } \\
\text { e profissionais na gestão do negócio. }\end{array}$ & 4,46 & 0,94 \\
\hline $\begin{array}{l}\text { Competências gerenciais mobilizadas em decorrência do relacionamento } \\
\text { interno e externo. }\end{array}$ & 4,39 & 1,03 \\
\hline
\end{tabular}

Fonte: Dados da pesquisa (2018). Extraídos do software SPSS 19.0.

Dessa forma, os resultados das médias por categoria (tabela 2) demonstram que os gestores dos empreendimentos rurais entrevistados mobilizam mais em primeiro lugar as competências gerenciais decorrentes das habilidades técnicas e profissionais na gestão do negócio (média igual a 4,46). E as principais deficiências encontram-se nos conhecimentos, atualizações e monitoramento do ambiente competitivo do negócio com menor média $(3,79)$.

\subsection{Competências gerenciais que impactam o desempenho financeiro}

Para a avaliação de quais variáveis independentes (competências gerenciais), de fato, tinham alguma relação com a variável desempenho financeiro, e, assim, definir o modelo inicial da regressão linear a ser testado, foi aplicada a prova paramétrica da correlação de Pearson (tabela 3), em razão da constatação da normalidade dos dados. Foi considerado um nível de significância igual a 0,05 e, por esse motivo, se o valor da coluna $\mathrm{P}$ - valor fosse < 0,05 , havia correlação entre as variáveis testadas, caso contrário não.

Tabela 3: Correlação de Pearson entre as competências gerenciais e o desempenho financeiro

\begin{tabular}{|c|c|c|c|c|}
\hline Fatores & $\mathrm{P}$ & $\begin{array}{l}\text { Coeficiente de } \\
\text { correlação de Pearson } \\
\text { (Rho) }\end{array}$ & $\begin{array}{l}\text { P- } \\
\text { valor } \\
\text { (Sig) }\end{array}$ & $\begin{array}{c}\text { Análise } \\
\text { S(1) }\end{array}$ \\
\hline \multirow{8}{*}{$\begin{array}{c}\text { COMPETÊNCIAS GERENCIAIS } \\
\text { MOBILIZADAS EM DECORRENCIA DOS } \\
\text { CONHECIMENTOS, DAS } \\
\text { ATUALIZAÇÕES E } \\
\text { DO MONITORAMENTO } \\
\text { DO NEGÓCIO }\end{array}$} & P1 & $-0,049$ & 0,798 & NS \\
\hline & $\mathrm{P} 2$ & $-0,309$ & 0,097 & NS \\
\hline & P3 & 0,306 & 0,100 & NS \\
\hline & $\mathrm{P} 4$ & 0,184 & 0,329 & $\mathrm{NS}$ \\
\hline & P6 & 0,082 & 0,667 & $\mathrm{NS}$ \\
\hline & P7 & 0,409 & 0,025 & $\mathrm{~S}$ \\
\hline & P8 & 0,407 & 0,028 & $\mathrm{~S}$ \\
\hline & P9 & $-0,106$ & 0,576 & $\mathrm{NS}$ \\
\hline \multirow{8}{*}{$\begin{array}{c}\text { COMPETÊNCIAS GERENCIAIS } \\
\text { MOBILIZADAS EM DECORRENCIA DAS } \\
\text { HABILIDADES TÉCNICAS } \\
\text { E } \\
\text { PROFISSIONAIS } \\
\text { NA GESTÃO DO NEGÓCIO }\end{array}$} & P11 & 0,053 & 0,770 & $\mathrm{NS}$ \\
\hline & P13 & 0,345 & 0,062 & NS \\
\hline & P14 & 0,161 & 0,394 & NS \\
\hline & P16 & 0,431 & 0,018 & $\mathrm{~S}$ \\
\hline & P17 & 0,371 & 0,044 & $\mathrm{~S}$ \\
\hline & $\mathrm{P} 18$ & 0,465 & 0,010 & $\mathrm{~S}$ \\
\hline & P19 & 0,198 & 0,295 & NS \\
\hline & $\mathrm{P} 20$ & $-0,444$ & 0,014 & $\mathrm{~S}$ \\
\hline \multirow{3}{*}{$\begin{array}{c}\text { COMPETÊNCIAS GERENCIAIS } \\
\text { MOBILIZADAS EM DECORRENCIA DO } \\
\text { RELACIONAMENTO }\end{array}$} & $\mathrm{P} 21$ & 0.431 & 0.018 & $\mathrm{~S}$ \\
\hline & $\mathrm{P} 22$ & 0,464 & 0,010 & $\mathrm{~S}$ \\
\hline & $\mathrm{P} 23$ & 0,542 & 0,002 & $\mathrm{~S}$ \\
\hline
\end{tabular}

Persp. online: hum. \& sociais aplicada., Campos dos Goytacazes, 24 (9),47-68, 2019 


\begin{tabular}{|c|c|c|c}
\hline P24 & 0,352 & 0,056 & NS \\
\hline P25 & $-0,485$ & 0,007 & S \\
\hline P26 & 0,367 & 0,046 & S \\
\hline P27 & 0,164 & 0,303 & NS \\
\hline P28 & 0,195 & 0,303 & NS \\
\hline P29 & 0,168 & 0,384 & NS \\
\hline
\end{tabular}

Fonte: Dados da pesquisa (2018) processados no programa SPSS 19.0.

(1) Nesta coluna S representa significante e NS não significante a um nível de 5\%.

Os resultados da tabela 3 apontam que há correlação do desempenho financeiro com as seguintes variáveis de competências gerenciais levantadas: P7, P8, P16, P17, P18, P20, P21, P22, P23, P25 e P26. A partir dessas correlações, foi realizada a análise de regressão linear, objetivando verificar se as variáveis independentes correlacionadas com a variável dependente impactavam realmente essa última. Utilizou-se o método de regressão linear múltipla, que tem como finalidade testar o grau de relacionamento entre uma variável dependente e duas ou mais varáveis independentes, (HAIR et al., 2014). Foram excluídas da análise as variáveis que não se correlacionaram com a variável dependente, ou seja, aquelas que não obtiveram como resultado p-valor abaixo de 0,05 (tabela 3 ).

O modelo da equação testado inicialmente foi o seguinte:

$D F=\beta_{0}+\beta_{1} P 7+\beta_{2} P 8+\beta_{3} P 16+\beta_{4} P 17+\beta_{5} P 18+\beta_{6} P 20+\beta_{7} P 21+\beta_{8} P 22 \quad \beta_{9} P 23+$ $\beta_{10} P 25+\beta_{11} P 26$. Sendo que:

$D F$ - representa a variável dependente: o desempenho financeiro (renda média) das MPEs.

P7, P8, P16, P17, P18, P20, P21, P22, P23, P25 e P26- as competências gerenciais relacionadas.

$\beta 0, \beta 1, \beta 2, \beta 3, \beta 4, \beta 5, \beta 6, \beta 7, \beta 8, \beta 9, \beta 10$ e $\beta 11$ - representam os coeficientes a serem estimados das variáveis independentes.

$\mathrm{Na}$ primeira rodagem do modelo acima, as variáveis P8, P16 e P17 apresentaram níveis de significância altos (bem acima de 0,05) e por isso foram excluídas do modelo, realizando-se a seguir uma segunda rodagem do teste da regressão linear. Com essas variáveis excluídas, o novo modelo ficou mais ajustado, e os resultados, nas tabelas 4, 5, 6 e 7, mostram sequencialmente os indicadores de avaliação do modelo de regressão, os coeficientes de regressão, o teste a Nova e os procedimentos realizados para validação do modelo.

Tabela 4: Coeficientes do modelo das variáveis testadas

\begin{tabular}{c|c|c|c|c|c|c}
\hline \multicolumn{5}{c}{ Modelo } & \multicolumn{3}{c}{ Estatísticas da coloneidade } \\
\hline Variável & Coeficiente & Erro padão. & T & Sig. P-valor & Tolerância & VIF \\
\hline (Constante) & 265,310 & 202,418 & 1,311 & 0,204 & & \\
\hline P7 & 25,450 & 12,062 & 2,110 & 0,047 & 0,785 & 1,273 \\
\hline P18 & $-58,165$ & 35,091 & $-1,658$ & 0,112 & 0,223 & 4,478 \\
\hline P20 & $-32,602$ & 17,047 & $-1,912$ & 0,070 & 0,591 & 1,691 \\
\hline P21 & $-146,159$ & 75,552 & $-1,935$ & 0,067 & 0,124 & 8,033 \\
\hline
\end{tabular}

Persp. online: hum. \& sociais aplicada., Campos dos Goytacazes, 24 (9),47-68, 2019 seer.perspectivasonline.com.br 


\begin{tabular}{c|c|c|c|c|c|c}
\hline P22 & 77,876 & 45,481 & 1,712 & 0,102 & 0,244 & 4,091 \\
\hline P23 & 71,266 & 26,076 & 2,733 & 0,012 & 0,316 & 3,168 \\
\hline P25 & $-30,533$ & 13,701 & $-2,229$ & 0,037 & 0,682 & 1,467 \\
\hline P26 & 51,857 & 31,875 & 1,627 & 0,119 & 0,234 & 4,270 \\
\hline
\end{tabular}

Fonte: Dados da pesquisa (2018). Extraídos do software SPSS 19.0.

Nota: p-valor $<0,05$ (nível de confiança 95\%).

Os resultados obtidos na pesquisa indicam que três competências gerenciais avaliadas pelos gestores, a um nível de significância de 0,05 , têm impacto no desempenho financeiro das micro e pequenas empresas. A P23, que se apresentou com maior força de explicação do desempenho financeiro (tabela 4, coluna $\mathrm{T}$, valor igual a 2,733), verificou se o gestor tem sido flexível e aberto às mudanças necessárias para melhorar a vantagem competitiva do estabelecimento que administra ( p- valor igual a 0,012).

Nesse sentido, as organizações precisam ser competitivas e para isso flexíveis o suficiente para se amoldarem às imposições de um mercado mais rápido e globalizado (GATTAI, 2013). Ou seja, as PMEs precisam, dentro do ambiente de negócios com suas constantes mutações, de gestores competentes o suficiente para saberem mobilizar a capacidade em lidar de forma proativa com as situações ambíguas e complexas (CHANG; THARENOU 2008). Além disso, gestores necessitam não somente mobilizar competências profissionais ou ser experientes em habilidades orientadas para tarefas, mas também devem ser receptíveis as mudanças e adaptar-se às novas oportunidades (FATOKI, 2014). Assim, o processo de gestão ativa e flexível pode ajudar as organizações a se posicionar com uma maior vantagem competitiva em seu mercado de atuação e a melhorar o seu desempenho financeiro ( FLEURY; FLEURY, 2011).

A segunda, a P7, ( tabela 4, coluna com p-valor de 0,047) avaliou se o gestor tem buscado informações e conhecimentos de negócios com outros gestores de outros empreendimentos similares pertencentes a mesma localidade, e, ao utilizá-los, tem conseguido bons resultados. Há necessidade de as MPEs serem encorajadas para que as ideias e informações sejam compartilhadas, diminuído a assimetria de informações e também para que a abordagem de gestão seja mais analítica e menos intuitiva do que é tão comum nesse tipo de empresa ( HAYTON, 2015). Nesse sentido, ao compartilhar informações sobre seus negócios, os gestores podem refletir sobre a compreensão da organização, sua estratégia, estrutura e como um todo dentro do ambiente em que está inserido.

E a terceira, P25, em que analisou se há participação do gestor em grupos ou associações ligados ao seu empreendimento, e, por isso, está buscando outras soluções que agreguem valor competitivo para o estabelecimento que administra (tabela 4, coluna p- valor igual 0,037. Há a necessidade do esforço coletivo entre os gestores das MPEs, com objetivo de partilhar, expandir e diversificar suas operações, buscando dessa forma criar melhores oportunidades em suas áreas de atuação. E isto poderá propiciar o tão indispensável alicerce de recursos vigorosos que faltam nas MPEs ( FLEURY; FLEURY, 2011).

Analisando-se a tabela 5, o valor medido pelo $\mathrm{R}^{2}$ (R- quadrado) explica o quanto as variáveis independentes influenciam na variação da variável dependente, ou seja, no caso do modelo testado, a P7, P23 e P25 explicam 63,90\% (0,639 x 100) na alteração no desempenho financeiro. Sendo considerado esse resultado como bom, confirmando assim que a relação entre as variáveis é forte. A partir desse quadro, pode-se afirmar que há suficiente impacto das competências gerenciais no desempenho financeiro das MPEs analisadas.

Persp. online: hum. \& sociais aplicada., Campos dos Goytacazes, 24 (9),47-68, 2019 seer.perspectivasonline.com.br 
Tabela 5: Resumo do modelo de regressão linear múltipla

\begin{tabular}{|l|c|l|l|l|l|}
\hline Modelo & $\mathrm{R}$ & $\mathrm{R}$ cuadrado & $\mathrm{R}$ cuadrado corregido & Error típico & Durbin-Watson \\
\hline 1 & $0,799 \mathrm{a}$ & 0,639 & 0,501 & 83,734 & 2,622 \\
\hline
\end{tabular}

Fonte: Dados da pesquisa (2018). Extraídos do software SPSS 19.0.

Na tabela 6 , o teste a NOVA, a nível de significância de 0,05 , respondeu se o modelo ajustado era significativo.Com o p-valor de 0,002 (abaixo de 0,05) sugere que pelo menos uma das variáveis independentes exerce influência sobre o desempenho financeiro.

Tabela 6: Teste a NOVA

\begin{tabular}{c|c|c|c|c|c}
\hline Modelo & $\begin{array}{c}\text { Soma dos } \\
\text { quadrados }\end{array}$ & $\begin{array}{c}\text { Graus de } \\
\text { liberdade }\end{array}$ & Media quadrática & F & Sig P-valor \\
\hline Regressão & 260.642 & 8 & 32.580 & 4,647 &, 002 \\
\hline Residual & 147.238 & 21 & 7.011 & & \\
\hline Total & 407.880 & 29 & & & \\
\hline \multicolumn{6}{c}{ Nota: p-valor $<0,05 * *$ (nível de confiança 95\%) }
\end{tabular}

Fonte: Dados da pesquisa (2018). Extraídos do software SPSS 19.0.

Foram também analisados os pressupostos para a validade do modelo da regressão que são: autocorrelação dos resíduos, normalidade dos resíduos, homocedasticidade, erro de especificação, ausência ou não de multicolinearidade e verificação da possibilidade de falha estrutural no modelo. O nível de significância adotado para se testar as conjecturas do modelo foi de 0,05 e os resultados foram apresentados na tabela 7 .

Tabela 7: Pressuspostos testados para a validação da Regressão Linear Múltipla.

\begin{tabular}{|c|c|c|}
\hline Pressupostos & Testes & \begin{tabular}{|c|} 
Hipóteses \\
\end{tabular} \\
\hline $\begin{array}{l}\text { Autocorrelação dos } \\
\text { resíduos }\end{array}$ & Durbin-Watson: Estatística DW =2,622. & $\begin{array}{l}\text { Inexiste autocorrelação entre os } \\
\text { resíduos (resultado com valor próximo } \\
\text { de 2,0 é considerado satisfatório). }\end{array}$ \\
\hline $\begin{array}{l}\text { Normalidade dos } \\
\text { resíduos }\end{array}$ & P- valor $=0,360$ & $\begin{array}{l}\text { A distribuição dos resíduos é normal } \\
\text { (p-valor acima de } 0,05 \text { é considerado } \\
\text { satisfatório). }\end{array}$ \\
\hline $\begin{array}{l}\text { Homocedasticidade } \\
\text { (Linearidade dos } \\
\text { resíduos) }\end{array}$ & Teste de White: Estatística: $\quad \mathrm{P}$-valor $=0,441$ & $\begin{array}{l}\text { A distribuição dos resíduos é normal } \\
\text { (p-valor acima de } 0,05 \text { é considerado } \\
\text { satisfatório). }\end{array}$ \\
\hline Erro de especificação & Teste de Reset de Ramsey: P- valor $=0,429$ & $\begin{array}{l}\text { Não há erros de medidas, nem } \\
\text { exclusão de variável relevante (p-valor } \\
\text { acima de } 0,05) .\end{array}$ \\
\hline $\begin{array}{l}\text { Ausência ou não de } \\
\text { multicolinearidade }\end{array}$ & $\begin{array}{l}\text { Teste VIF (Fator de Inflação da Variância): } \\
\text { VIF }=1,273,4,478,1,698,8,033,4,091,3,198, \\
1,467 \text { e } 4,270 \text { pra todas as variáveis incluídas no } \\
\text { modelo final. }\end{array}$ & $\begin{array}{l}\text { Ausência de multicolinearidade }(\mathrm{As} \\
\text { variáveis que apresentem resultados } \\
\text { com valores abaixo de } 10 \text { são } \\
\text { consideradas satisfatórias). }\end{array}$ \\
\hline $\begin{array}{l}\text { Verificação da } \\
\text { possibilidade de falha } \\
\text { estrutural no modelo }\end{array}$ & Teste de Show: P- valor $=0,535$ & $\begin{array}{l}\text { Não há falha estrutural no modelo } \\
\text { porque p-valor acima de } 0,05 \text { é } \\
\text { considerado satisfatório). }\end{array}$ \\
\hline
\end{tabular}

Fonte: Dados da pesquisa (2018). Extraídos do software SPSS 19.0. 
Para a verificação se os erros eram independentes, ou seja, se não havia autocorrelação dos resíduos, foi utilizado o teste de Durbin-Watson; valores próximos de 2 indicam que os erros são independentes (MAROCO, 2014). Com o resultado de 2,622, na tabela 7, foi satisfeita a primeira condição do modelo, ou melhor, os resíduos não se correlacionam.

$\mathrm{Na}$ análise se os resíduos seguiam uma distribuição normal ou não, a um nível de significância de 0,05 , (valores acima deste rejeita-se a hipótese de que os resíduos não seguem uma distribuição normal), o resultado do P-valor igual a 0,360 (tabela 7) atendeu ao quesito da aceitação da hipótese nula, ou seja, confirmando a normalidade dos resíduos. Assim, é atendida a segunda condição para a aplicação do modelo da regressão linear (HAIR et al., 2014). O teste de White verificou a homocedasticidade ou a linearidade ou não dos resíduos (HAIR et al., 2014). Em outras palavras, buscou analisar se havia ou não a apresentação de dados muito diferentes, supressão de variáveis ou desproporção na disposição de um ou mais dos repressores. Com o P-valor de 0,441 (tabela 7), atendeu-se também esse critério.

Foi realizado o teste Reset de Ramsey que é indicado para a averiguação de erro de especificação do modelo de regressão analisado. E que pode ocorrer por supressão de variável relevante, inclusão de variável sem relevância ou por falhas de medida. Como o resultado (tabela 7) foi acima de 0,05 , considera-se que a especificação do modelo é apropriada, cumprindo assim esse requisito para a validade da regressão linear. Além disso, na verificação da possibilidade de falha estrutural no modelo através do Teste de Chow, o resultado do Pvalor de 0,535 (acima de 0,05) demonstrou que essa condição também foi cumprida.

Avaliando-se se as variáveis explicativas estavam muito correlacionadas (multicolinearidade), uma em função da outra, realizou-se o teste VIF (Fator de Inflação da Variância). Os valores resultantes da aplicação dessa prova indicam ausência de multicolinearidade (tabela 7), porque valores menores que dez (10) satisfazem esse requisito. (HAIR et al., 2014). Todas as variáveis do modelo ficaram com escores abaixo desse critério.

Enfim, após a validação do modelo de regressão linear e examinado que as variáveis P7, P23 e P25 impactam o desempenho financeiro das MPEs analisadas, extraiu-se a seguinte equação final da regressão linear representativa das variáveis independentes influentes na variável dependente: $D F=\beta_{0}+\beta_{1} P 7+\beta_{2} P 23+\beta_{3} P 25$.

\section{CONCLUSÕES}

As pesquisas sobre as MPEs têm procurado elucidar as razões de muitas delas não conseguirem sobreviver e fecharem suas portas precocemente. Nesse sentido, vários fatores são elencados pela literatura no assunto, entre eles as competências de seus gestores. Como novidade de averiguação, esse estudo procurou verificar se as competências gerenciais mobilizadas pelos gestores de MPEs têm impacto no desempenho financeiro nesse tipo de empresa, a partir de um conjunto de MPEs rurais.

A investigação aqui exposta demonstrou ligações preditivas positivas de competências gerenciais para o bom desempenho financeiro das MPEs pesquisadas. Em termos numéricos, as competências de gestão determinam positivamente $63,90 \%$ do nível de desempenho das MPEs avaliadas. Sendo que três competências gerenciais mobilizadas pelos gestores têm impacto no desempenho financeiro das MPEs. Esse resultado, especificamente nessas três competências gerenciais influenciadoras do desempenho financeiro, indica que é preciso haver uma gestão ativa e flexível, principalmente na busca de informações e conhecimentos

Persp. online: hum. \& sociais aplicada., Campos dos Goytacazes, 24 (9),47-68, 2019 seer.perspectivasonline.com.br 
que agreguem valor para a compreensão do negócio como um todo dentro do ambiente em que a organização está inserida.

A partir desses achados do estudo, em consonância com a literatura existente, é possível estender o debate do papel importante das competências gerenciais no desempenho financeiro das MPEs do âmbito rural. Além do que, essas conclusões acrescentam também que há razões para dar mais importância às iniciativas que procuram estimular as MPEs do setor rural a aprimorar suas competências de gestão. Acredita-se também que a pesquisa contribuiu de alguma forma para que haja continuidade de estudos sobre o tema nas MPEs situadas no âmbito rural. Reconhece-se como limitações dessa pesquisa a quantidade de MPEs da amostra, a sua restrição a uma só localidade rural e também uma certa subjetividade dos dados coletados, uma vez que se tratou também de autoavaliação de competências por parte de gestores.

Portanto, diante dessas ponderações e dada à importância do assunto, recomenda-se que sejam explorados novos estudos referentes ao tema, aumentando o número da amostra de MPEs e ainda considerando outras localidades rural.

\section{REFERÊNCIAS}

BARBOSA, A. C. Q.; CINTRA, L. P. Inovação, Competências e desempenho organizacional: articulando construtos e sua operacionalidade. Future Studies Research Journal: Trends and Strategies, vol. 4, $\mathrm{n}^{\mathrm{o}}$ 1, p. 31-60, 2012.

BELMONTE; V. A. B., FREITAS; W. R. S. Empresas familiares e a profissionalização da gestão: estudos de casos em empresas paulistas. Revista de Administração, UFSM, Santa Maria, vol. 6, $\mathrm{n}^{\mathrm{o}}$. 1, p. 71-90, 2013.

BITENCOURT, C.; BARBOSA, A. Gestão de competências: articulando indivíduos, organizações e sociedade. In: BITENCOURT, Cláudia (Org.). Gestão contemporânea de pessoas. Porto Alegre: Bookman, 2010.

BOHN, A. C. ; GAMBIRAGE, C. ; SILVA, J. C. ; HEIN, N. ; IARGAS, A. I. Fatores que impactam no encerramento prematuro de empresas de pequeno porte: estudo no litoral de Santa. Navus, Florianópolis- SC, vol.8, nº 2, p. 43-56, 2018.

BOYATZIS, R. E. Competencies in the $21^{\text {st }}$ century. Journal of Management Development. Emerald Group Publishing Limited, vol. 27, $\mathrm{n}^{\mathrm{o}}$. 1, p. 5-12, 2008.

BROSZEIT S.; FRITSCH, U.; GÖRG, H.; MARIE, C. L. Management practices and productivity in Germany. Institute for Employment Research, Nuremberg, no 32, 2016.

BRYSON, A.; FORTH, J. The impact of management practices on Sme performance. National Institute of Economic and Social Research, ${ }^{\circ}$ 488, 2018.

CARDOSO, J. F.; RAIMUNDO, P. J. Índices de desempenho para micro e pequenas empresas: um estudo no segmento de alimentação fora do lar. Revista Empreendedorismo, Gestão e Negócios, vol. 3, nº 3, p. 189-208, 2014.

CHANG, K.T.; THERENOU, L.C. Competencies needed for managing a multicultural workgroup. Contemporary Management Res., vol. 3 n 3, p. 213-232, 2008.

COSTA, A.C. Competências gerenciais dos gestores da rota turística rural caminho do vinho.131 p. Dissertação (Mestrado em Administração) - Faculdade de Campo Limpo Paulista, Campo Limpo Paulista- SP, 2016.

Persp. online: hum. \& sociais aplicada., Campos dos Goytacazes, 24 (9),47-68, 2019 
CRESWELL, J. W. Investigação qualitativa e projetos de pesquisa. Porto Alegre: Penso, 2014.

DAHMEN, P.; RODRIGUEZ, E. Financial Literacy and the Success of Small Businesses: An Observation from a Small Business Development Center. Numeracy, vol. 7, $\mathrm{n}^{\mathrm{o}}$ 1, 2014.

DUTRA, J. S. Competências - Conceitos e instrumentos para gestão de pessoas na empresa moderna. São Paulo: Atlas, 2013.

ESPEJO, M. M. S. B.; LEITE, H. O. Desempenho de micro e pequenas empresas: um estudo a luz das características do empreendedor - gestor e do controle gerencial. Ribeirão Preto: X Congresso Anpcont., 2016.

EVERTON JUNIOR, A. Avanços importantes para as micro e pequenas empresas. Confederação Nacional do Comércio de Bens, Serviços e Turismo, Rio de Janeiro, 2017.

FATOKI, O. The impact of managerial competencies on the performance of immigrantowned enterprises in South Africa. Mediterranean Journal of Social Sciences. vol. $5 \mathrm{n}^{\circ}$ 6, $\mathrm{p}$. 141-144, 2014.

FERREIRA, L. F. F.; SANTOS, S. A.; GRISI, C. C. H.; LIMA, A. C. Análise quantitativa sobre a mortalidade precoce de micro e pequenas empresas da cidade de São Paulo. Gestão e Produção, vol. 19, nº . 4, p. 811-823, 2012.

FLEURY, A.; FLEURY, M. T. L. Estratégias empresariais e formação de competências: um quebra-cabeça caleidoscópio da indústria brasileira. 3ª ed. São Paulo: Atlas, 2011.

FREIRE, D. A. L. Análise do Potencial de Crescimento das Micro e Pequenas Empresas (MPEs) Brasileiras. Revista da Micro e Pequena Empresa, vol. 10, ñ 1, p. 12-28, 2016.

FREITAS, P. F. P.; ODELIUS, C.C. Competências gerenciais: uma análise de classificações em estudos empíricos. Cad. Ebape, vol. 16, nº 1, Rio de Janeiro, p. 35-49. 2018.

HAIR Jr, J. F; CELSI, M. W; ORTINAU, D. J.; BUSH, R. P. Fundamentos de Pesquisa de Marketing. 2. ed. Porto Alegre: Bookman, 2014.

HAYTON, J. Leadership and Management Skills in SMEs: Measuring Associations with Management Practices and Performance. Enterprise Research Centre/Warwick Business School, $n^{\circ}$ 211, p.1-39, 2015.

HAUBERT, F. L. C.; NASCIMENTO, M. Avaliação de desempenho de micro e pequenas empresas fundamentada na metodologia meda-c na cidade de Lages. Future Studies Research Journal, vol. 5, nº 2, p. 79-112, 2013.

KATUA, N.T. The Role of SMEs in Employment Creation and Economic Growth in Selected Countries. International Journal of Education and Research, vol. $2 \mathrm{n}^{\circ} .12,2014$.

LANDRY, S.; SCHIEHLL, E. Percepção de Controlabilidade e Equidade da Avaliação de Desempenho. Revista Brasileira de Gestão e Negócios, vol. 16, n 52, p. 484-503, 2014.

LE BOTERF. Apprendre à agir et à interagir en professionel compétent et responsable. Paris: Education Permanente, 2011.

LEMOS, A.Q. e PICCHIAI, D. Práticas de Gestão e Desempenho Financeiro: Um Estudo Realizado em Empresas da Região de Campo Limpo Paulista. Editora Unijuí, vol. 12, n 25, pp.279- 311, 2014.

LEONE, R. J.G; LEONE, N. M. Pequenas e médias empresas: contribuições para a discussão sobre por que e como medir o seu tamanho. Revista do Mestrado em Administração da Universidade Potiguar - RaUnP, vol. 4, nº 1, p.67-83, 2012.

Persp. online: hum. \& sociais aplicada., Campos dos Goytacazes, 24 (9),47-68, 2019 seer.perspectivasonline.com.br 
MCCLELLAND, D. C. Testing for competence rather than for "intelligence". American Psychologist, [S.l.], 1973. Disponível em: <http://scholar.google.com.br/scholar? $\mathrm{hl}=\mathrm{ptBR} \& \mathrm{q}=$ mcclelland $\& b \operatorname{tnG}=\& 1 \mathrm{r}=>$. Acesso em: 5 ago. 2015.

MACEDO, M. A. S.; MARQUES, J. A. V. C.; RIBEIRO, M. G. C. Análise da relevância de indicadores financeiros e não financeiros na avaliação de desempenho organizacional: um estudo exploratório no setor brasileiro de distribuição de energia elétrica. Revista de Contabilidade e Organizações, vol. 6, $\mathrm{n}^{\mathrm{o}}$ 15, p. 60-79, 2012.

MACHADO, T. R. B; SORNBERGER, G. P; COAN, F. M. J. Avaliação de desempenho organizacional em pequenas e médias empresas: estudo multicaso em concessionárias de máquinas e implementos agrícolas. Revista Contabilidade e Controladoria, vol. 7, nº 3, 2015.

MALHOTRA, N. Pesquisa de marketing: uma orientação aplicada. 6. ed. Porto Alegre: Bookman, 2012.

MAROCO, J. Análise estatística com o SPSS Statistics. 6 ${ }^{\text {a }}$ ed. Pero Pinheiro: Report Number, 2014.

MINISTÉRIO DO DESENVOLVIMENTO, INDÚSTRIA E COMÉRCIO EXTERIORSECRETARIA DO COMÉRCIO EXTERIOR- SECEX. Disponível em: http://www.mdic.gov.br/index.php/comercio-exterior/estatisticas-de-comercio-exterior/outrasestatisticas-de-comercio-exterior. Acesso em 04/03/2017.

MINTZBERG, H. Managing. Desvendando o dia a dia da gestão. Porto Alegre: Bookman, 2010 .

NASCIMENTO, M. et al. Fatores determinantes da mortalidade de micro e pequenas empresas da região metropolitana de Florianópolis sob a ótica do contador. Revista Eletrônica de Estratégia \& Negócios, vol. 6, nº. 2, p. 244-283, 2013.

NASCIMENTO, S. do; BORTOLUZZI, S. C.; DUTRA, A.; ENSSLIN, S.R. Mapeamento dos indicadores de desempenho organizacional em pesquisas da área de Administração, Ciências Contábeis e Turismo no período de 2000 a 2008. Rev. Adm., São Paulo, vol.46, $\mathrm{n}^{\mathrm{o}} .4, \mathrm{p} .373-391,2011$.

ORGANISATION FOR ECONOMIC COOPERATION AND DEVELOPMENT- OECD. Small, Medium, Strong. Trends in SME Performance and Business Conditions, OECD Publishing, Paris, 2017.

PALMA, E. P., GOMES, C. M., KNEIPP, J. M.; ROSA, L. A. B. Estratégias de negócios sustentáveis e desempenho exportador: uma análise em empresas do setor de gemas e joias. Revista Brasileira de Gestão de Negócios, vol. 16, nº 50, p. 25-42, 2014.

PASSOS, C. A.; SPERS, R. G. Modelo de avaliação de desempenho organizacional para pequenas e médias empresas. Revista Ibero-Americana de Estratégias, vol. 13, n. 4, 2014.

REIS NETO, J. F. D.; MUÑOZ. G., P. A.; SOUZA, C. C.; RODRIGUES, W. O. P. As conexões entre orientação empreendedora, capacidade de marketing e a percepção do desempenho empresarial: evidências empíricas das micro e pequenas empresas varejistas. Revista de Administração Mackenzie, vol. 14, nº, p. 236-271, 2013.

RICHARDSON, R. J. Pesquisa social: métodos e técnicas. 4ª ed. São Paulo: Atlas, 2017.

RUAS, R. Desenvolvimento de Competências Gerenciais e Contribuição da Aprendizagem Organizacional. In: FLEURY, Maria Tereza Leme; OLIVEIRA JR, Moacir

Persp. online: hum. \& sociais aplicada., Campos dos Goytacazes, 24 (9),47-68, 2019 seer.perspectivasonline.com.br 
de Miranda (Org.). Gestão Estratégica do Conhecimento: Integrando aprendizagem, conhecimento e competências. São Paulo: Editora Atlas, 2010.

SANTANA, E. N.; CUNHA, L. P.; MARIZ, F. B. A. R. Indicadores de desempenho para micro e pequenas empresas: análise da literatura e estudo de caso. João Pessoa: XXXVI Encontro Nacional de Engenharia de Produção- Contribuições da Engenharia de Produção para Melhores Práticas de Gestão e Modernização do Brasil, 2016.

SANT'ANNA, A.S. et al. Competências individuais e modernidade organizacional: um estudo comparativo entre profissionais de organizações mineiras e baianas. Gest. Prod. [online], vol. 23, no. 2, p.308-319, 2016.

SANTINI, S. et al. Fatores de mortalidade em micro e pequenas empresas: Um estudo na região central do Rio Grande do Sul. Revista Eletrônica de Estratégia e Finanças, Florianópolis, vol.8, $\mathrm{n}^{\mathrm{o}} .1,2015$.

SANTOS, V.; DOROW, D. R.; BEUREN, I. M. Práticas Gerenciais de Micro e Pequenas Empresas. Revista Ambiente Contabil, Natal-RN, v. 8, n. 1, p. 153-186, 2016.

SCHACHTER, H. Objective and Subjective Performance Measures A Note on Terminology. Administration \& Society, vol.42, $\mathrm{n}^{\mathrm{o}}$ 5, p. 550-567, 2010.

SCHMIDT, S.; BOHNENBERGER, M. C. Perfil empreendedor e desempenho organizacional. Revista de Administração Contemporânea, vol. 13, nº 3, p. 450-467, 2009.

SERVIÇO BRASILEIRO DE APOIO ÀS MICRO E PEQUENAS EMPRESAS - SEBRAE. 2016. Boletim: Estudos e Pesquisas, Brasília, $n^{0}$ 51, abril de 2016. Disponível em: https://m.sebrae.com.br/Sebrae/Portal\%20Sebrae/Anexos/boletim\%20estudos $\% 20 \mathrm{e} \% 20$ pesqu isas abril\%202016.pdf. Acesso em: 21/10/2016.

SERVIÇO BRASILEIRO DE APOIO ÀS MICRO E PEQUENAS EMPRESAS - SEBRAE. 2014. A evolução das Microempresas e Empresas de Pequeno Porte no Brasil. Brasília. Disponível

em: http://www.bibliotecas.sebrae.com.br/chronus/ARQUIVOS CHRONUS/bds/bds.nsf/800d694 ed9159de5501bef0f61131ad4/\$File/5175.pdf. Acesso em 10/03/2016.

SERVIÇO BRASILEIRO DE APOIO ÀS MICRO E PEQUENAS EMPRESAS - SEBRAE. 2014. Boletim estatístico de micro e pequenas empresas. Disponível em: $\leq$ www.sebrae.com.br $>$. Acesso em 07/02/2016.

SHEEHAN, M. Human resource management and performance: Evidence from small and medium-sized firms. International Small Business Journal (ISBJ), vol. nº 32, 2013.

SIDEK, S.; MOHAMAD, M. R. Managerial competencies and small business growth: empirical evidence from microfinance participants. IJMS , vol. 21, nº 1, p. 39-59, 2014.

SILVA, A. B. Como os gerentes aprendem. São Paulo: Saraiva, 2010.

SORIANO, D.R. Small business and entrepreneurship: their role in economic and social development. Entrepreneurship \& Regional Development, vol. 29, nº p.1-3, 2017.

SOUZA, A.C.; ALEXANDRE, N. M. C.; GUIRARDELlO, E. B. Propriedades psicométricas na avaliação de instrumentos: avaliação da confiabilidade e da validade. Epidemiol. Serv. Saude, Brasília, vol. 26, nº 3, 2017.

SOUZA, G.H; FELIX, L. A.; LAGIOIA, U. C. T.; GABRIEL, J.; ARAÚJO, N. Desempenho Financeiro e Divulgação de Informações sobre Recursos Humanos: uma Análise das Empresas do $\mathrm{IBrX}$ - 100. Revista de Educação e Pesquisa em Contabilidade, vol.10, $\mathrm{n}^{\mathrm{o}} 1$, p. $90-105,2016$.

Persp. online: hum. \& sociais aplicada., Campos dos Goytacazes, 24 (9),47-68, 2019 seer.perspectivasonline.com.br 
SOUZA, A. E.; CORREA, H. L. Indicadores de desempenho em pequenas e médias empresas. RPCA, Rio de Janeiro, vol. 8, nº 3, p.118-136, 2014.

SOUZA, M. C. A. F.; MAZZALI, L.;_SILVEIRA, R. L. F.; BACIC, M. J. Pequenas empresas industriais de longa permanência no mercado: uma análise a partir da literatura e de evidências empíricas. Revista Gestão e Produção, vol. 21, nº 1, p. 157-170, 2014.

SPENCER, L. M.; SPENCER, S. M. Competence at work: models for superior performance. New York: John Wiley \& Sons, 1993.

VELIU, L.; MANXHARI, M. The impact of managerial competencies on business performance: Sme's in kosovo. Journal of Management, vol. 30, no . 1, p. 59-65, 2017.

VIJ, S.; BEDI, H.S. . Are subjective business performance measures justified? International Journal of Productivity and Performance Management, vol. 65, nº 5, p. :603-621, 2016

WEGNER, D.; MISOCSKY, M. C. Avaliação de desempenho de redes de pequenas empresas: contribuições da abordagem da produção de sentido. Revista O\&S, vol.17, n.53, p.345-361, 2010.

WU, N.; HOQUE, K.; BACON, N.; LLUSAR, B.; CARLOS, J. High performance work systems and workplace performance in small, medium sized and large firms. Human Resource Management Journal, vol. 25 nº 4, p.408-423, 2015.

YILDIZ, S.; KARAKAŞ, A. Defining methods and criteria for measuring business performance: a comparative research between the literature in Turkey and foreign. Procedia Social and Behavioral Sciences, vol. 58, p.1091 - 1102, 2012.

ZARIFIAN, P. Objetivo competência: por uma nova lógica. São Paulo: Atlas, 2012.

ZULKIFFLI, S.A. Business Performance for SMEs: subjective or objective measures? Rev. Integr. Bus. Econ. Res., vol. 3, $\mathrm{n}^{\mathrm{o}}$ 1, p. 371-381, 20 